\title{
Monitoring and risk assessment due to presence of metals and pesticides residues in honey samples from the major honey producing forest belts and different brands
}

\author{
Ghazala YAQUB $^{1 *}$ (D), Mariyam KHALID ${ }^{1}$, Ayeza IKRAM ${ }^{1}$, Aimen SOHAIL ${ }^{1}$
}

\begin{abstract}
Honey is consumed worldwide because of its nutritional, therapeutic and medicinal purposes. Generally it is perceived that honey reaches its consumer in pure form however this is not always true as contaminants can end up in honey. Thus this study was designed to check the presence of contaminants in honey samples. For this purpose 52 samples were collected from forest belts while 25 samples of national and international brands were purchased. Heavy metals zinc, iron, cobalt and copper were detected in all 52 samples collected from forest belts. In honey brand samples coper ( 25 samples), cobalt (detected in 12 samples) and chromium (2 samples) were detected above their permissible limits and THQ (Target Hazard Quotient) was also found exceeding 1 for two samples in which cobalt was detected. Lambda Cyhalothrin and bifenthrin were the only pesticides detected in few samples collected from forest belts while Imidacloropid, Difenaconazole, Glyphosate and bifenthrin were detected above their permissible limit in few national and international brands. Health risk index calculations showed that in 4 samples collected from forest belts and one sample of honey brand in which bifenthrin was detected, HRI exceeded its threshold value of 1 showing its potential to pose significant health risk.
\end{abstract}

Keywords: honey; pesticides; target hazard quotient; health risk index.

Practical Application: Honey is consumed on a large scale throughout the world and becomes mandatory to carry out the monitoring and evaluation of the risk to the health of the consumers. This research was conducted and provides an easy and convenient approach to determine the concentration of trace metals and pesticides in honey samples and associated health risk by calculating Target Hazard Quotient (THQ) and Health Risk Index (HRI). The methods employed are easily adoptable, reliable and repeatable for future studies.

\section{Introduction}

This research is undertaken to check the presence of contaminants like trace metals and pesticides in honey samples collected from various areas of a developing country and to check the potential risk which the honey consumers are facing in Pakistan. Since rapid development in the field of agriculture is necessary for the economic growth of the country therefore the use of various chemicals and their release into the environment has increased considerably (Shahid et al., 2016; Tariq et al., 2007)

Therefore the second phase of this research focused on conducting a risk assessment to check the potential risk which the consumers of honey are facing in Pakistan. Extensive studies have been conducted defining the characterization, classification and medicinal importance of honey (Naila et al., 2018; Gregorio et al., 2019; Gregorio et al., 2018; Mehretie et al., 2018; Şeyda et al., 2017). Honey is a sweet thick liquid formed naturally by honey bees from the nectar that they have collected from flowers. The composition of honey depends on the type of flower from whose nectar it is made up of (Sohaimy et al., 2015). Honey basically consists of carbohydrates and water. However it also contains vitamins and mineral beneficial for human health. It is a high energy food which can provide its consumer with 64 calories per tablespoon (Kumar et al., 2010; Khan et al., 2007). Honey because of its antioxidant properties can eliminate free radicals from human body (Khalil et al., 2010). Honey is one of those gifts of nature that have benefited humans for ages due to its medicinal and therapeutic abilities i.e. it is consumed alone or in combination with other substance for various treatments (Molan, 1999). The therapeutic uses of honey include using it to heal various types of wounds because of its honey has antibacterial properties and wounds like diabetic, pressure and leg ulcers, burns and cuts can be healed with its application and usage (Group Health Cooperative 2010; Abeshu \& Geleta, 2016).

Honey dressings are used to reduce the smell, remove dead cells, reduce inflammation and promote rapid healing without the formation of scars or mark (Molan, 2002). The importance of honey is great because of its ability to fix, cure and treat a large number of problems (Kumar et al., 2010; Jull et al., 2013). Since honey is being consumed worldwide as a source of food and for medicinal purposes thus, it is essential that it remains in its pure state (Wieczorek et al., 2014). However different studies have shown its contamination due to pesticides, heavy metals, bacteria, and radioactive materials. These chemical are being released into the environment from anthropogenic sources and have the tendency to persist for a longer time. Pesticides, heavy metals and other contaminants can bio accumulate and 
bio magnifies in the food chain and play havoc with human health (Ali et al., 2019).

Therefore there is a need to limit the use and application of such substances (Waili et al., 2012). The main focus of this research is to determine the presence of heavy metals and pesticides in honey (i.e. collected from the forest belts and purchased from the local and international market) and to carry out risk assessment by calculating target hazard quotient i.e. a substance's potential exposure to the ratio of the level where it has no adverse effects and health risk index i.e. a screening tool which defines the promotion of health.

\section{Materials and methods}

The study area for this research consists of many scattered locations, geographically spread over South Punjab, Central Punjab, Northern Punjab, Central Khyber Pakhtunkhawa and Northern Areas of Pakistan (Figure 1).

For analysis total 52 samples were collected from 22 different locations. 25 samples of different national and international honey brands were also collected for the study. All the samples were given codes before further analysis. $40 \mathrm{~mL}$ of each sample was collected in sterilized vials and were stored in refrigerator at $4^{\circ} \mathrm{C}$ till further analysis.

\subsection{Selection of pesticides and heavy metals}

The pesticides analyzed in this study were: bifenthrin, lambda cyhalothrin, imidacloprid, dichlorovas, amamectin and glyphosphate as their spray was used in the nearby areas. Whereas the heavy metals selected were: zinc, iron, cobalt, manganese and chromium as in most of the previous studies they were reported in similar samples.

\subsection{Method for detection and determination of heavy metals}

\section{Sample digestion}

For sample preparation, two solutions were prepared using hydrogen peroxide, distilled water and nitric acid. Solution A consisted of $30 \mathrm{~mL}$ of hydrogen peroxide and $70 \mathrm{~mL}$ of distilled water whereas solution $\mathrm{B}$ consisted of $50 \mathrm{~mL}$ of nitric acid and $50 \mathrm{~mL}$ of distilled water. $1 \mathrm{~g}$ of honey sample was taken in a flask and $5 \mathrm{~mL}$ of solution $\mathrm{A}, 5 \mathrm{~mL}$ of solution $\mathrm{B}$ and $10 \mathrm{~mL}$ of deionized water were added to it. This mixture was then shifted to a round bottom flask and placed in a beaker containing silica gel. To keep the round bottom flask stable, a thermocol sheet was cut to form support and a lid. The flask was then heated for 40 seconds to digest the solution. However after every 10 seconds the flask was taken out and allowed to cool down. Once digested,

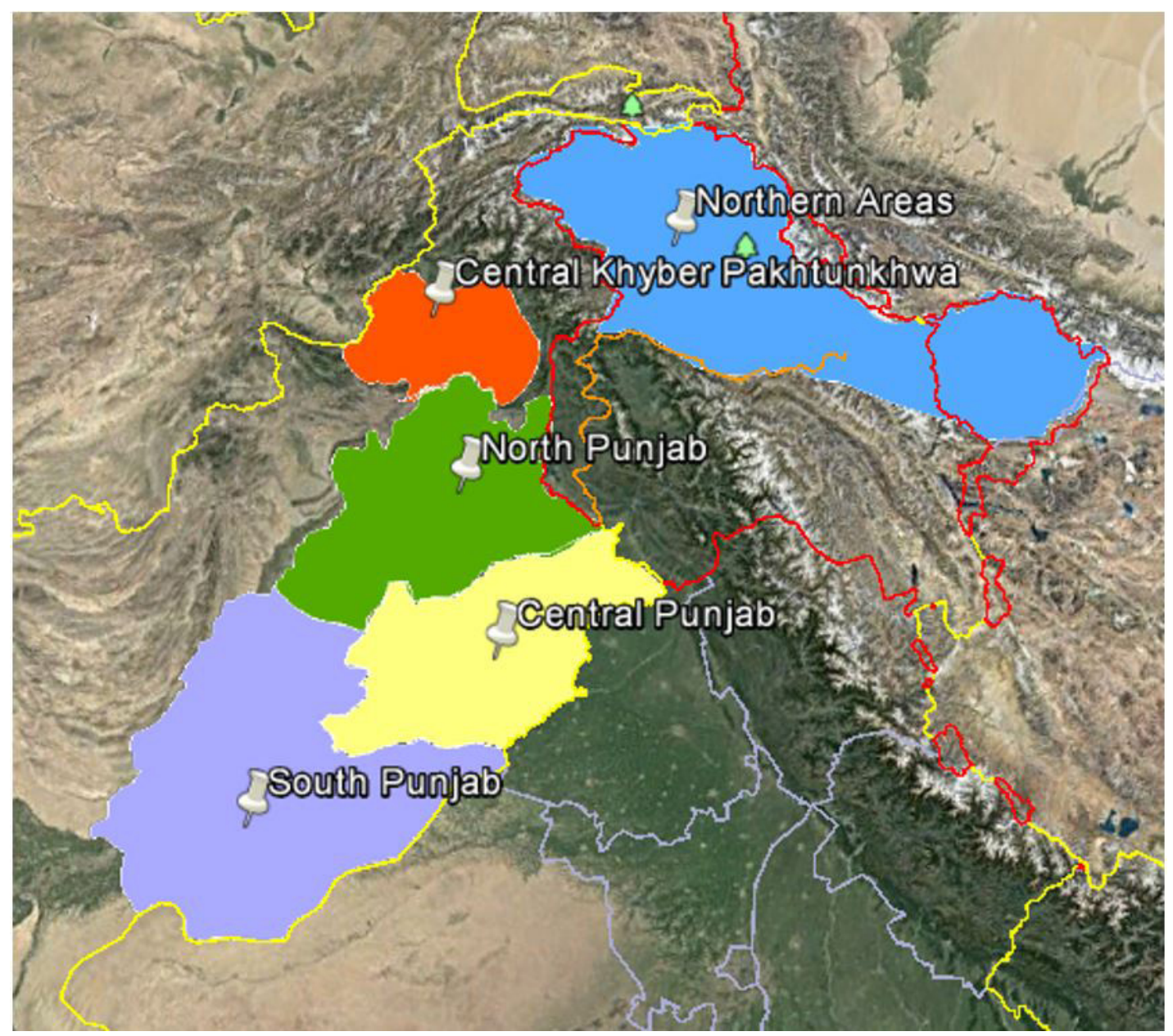

Figure 1. Map of Study Area. 
the solution was shifted into a volumetric flask and diluted with $100 \mathrm{~mL}$ of distilled water. The Heavy metals were detected by using atomic absorption spectroscopy.

\subsection{Risk assessment of heavy metals}

Risk assessment of heavy metals was carried out by calculating target hazard quotient for every metal and sample. This calculation was done to evaluate the risk pose by the consumption of contaminated honey. The oral reference dose taken has been prescribed by EPA and for zinc it was $0.3 \mu \mathrm{g}$ g- 1 day-1, for iron it was $0.7 \mu \mathrm{g}$ g- 1 day- 1 , for cobalt it was $0.001 \mu \mathrm{g}$ g- 1 day- 1 , in case of manganese it was $0.014 \mu \mathrm{g}$ g- 1 day- 1 and for chromium it was $0.001 \mu \mathrm{g}$ g- 1 day-1. THQ calculation has been designed and formulated by United States Environmental Protection Agency to determine the risk level in regard to heavy metals. It takes into account values of oral dose, amount and length of exposure, concentration of a specific metal and body weight. If the value of target hazard quotient exceeds 1 then this means that the consumers of that particular food are at risk.

The formula used in this calculation is given below (Naccari et al., 2014)

Target Hazard Quotient

$\mathrm{THQ}=[(\mathrm{EFr} \times \mathrm{EDtot} \times \mathrm{IFR} \times \mathrm{C}) /(\mathrm{RfDo} \times \mathrm{BWa} \times \mathrm{ATn})] \times 10^{-3}$

Where:

EFr: the exposure frequency (365 days/year) (122days/ year)

EDtot: is the exposure duration (66 year average life span)

IFR: is the food ingestion rate $(21.25 \mathrm{~g}$ day-1);

$\mathrm{C}$ : is the concentration ( $\mu \mathrm{g} g-1)$;

RfDo: is the oral reference dose ( $\mu \mathrm{g}$ g-1 day-1);

BWa: is the adult body weight $(60 \mathrm{~kg})$;

ATn: is the average time for non-carcinogens (it is equal to EFr x EDtot).

${ }^{\star}$ Oral reference dose $=\mathbf{0 . 0 0 1} \mu \mathrm{g} g-1$ day -1

\subsection{Sample preparation and pesticide detection in honey samples}

$5 \mathrm{~g}$ of honey sample was taken into a round bottom flask and $20 \mathrm{~mL}$ of Dichloromethane, $20 \mathrm{~mL}$ of ethyl acetate, $150 \mathrm{~mL}$ of distilled water and $5 \mathrm{~g}$ of sodium chloride was added in it. Then a magnetic stirrer was added to the mixture and flask was placed on a hot plate at 5 oscillation speed setting. Mixture was then stirred for about 30 mins and then transferred to a separating funnel. Organic and aqueous layers were both collected separately and $20 \mathrm{~mL}$ of Dichloromethane and $20 \mathrm{~mL}$ of ethyl acetate were added again to the aqueous layer to ensure complete extraction and organic layer was again collected. Organic layer was then filtered using a filter paper to remove any residues and $5 \mathrm{~g}$ of anhydrous sodium sulphate was added to it to remove any aqueous content. The mixture was filtered again and was dried in the rotary evaporator flask. Then finally $10 \mathrm{~mL}$ of methanol was added and this sample was then stored in a sterilized labeled vial for further analysis of pesticides. The analytical technique used to detect the presence of pesticides was HPLC Agilent 1260, Quaternary Gradient System. It is a type of column chromatography where sample is pumped from mobile phase to stationary phase at a very high pressure. C18 Licospher column was used with an Acetonitrile: Water (40:60) mobile phase at flow rate of $1.0 \mathrm{~mL} / \mathrm{min}$ at $25{ }^{\circ} \mathrm{C}$ column temperature. Injection volume was $5.000 \mu \mathrm{L}$ in order to validate the results. Each sample and standard was run in triplicate for quality assurance according to European commission guidelines. For method validation, optimization studies were performed on each HPLC parameter like solvent ratio, $\mathrm{pH}$, column temperature, sample/ injection volume, flow rate, wavelength and post time etc. System sensitivity, linearity, and peak area reproducibility were also evaluated. Recovery of pesticides was determined by spiking with a standard pesticide aqueous solution. For accuracy measurement the actual spiked value of samples were compared with the samples with known concentration of respective pesticides. Limit of detection (LOD) (3:1) and Limit of quantification (10:1) were calculated as signal to noise ratio. In current study Limit of detection (LOD) was 0.01 while Limit of quantification (LOQ) was $0.03 \mathrm{mg} / \mathrm{L}$ respectively. After qualitative assessment of the presence of pesticides in each sample, quantitative analysis was carried out to calculate the amount of detected pesticides.

\section{Results and discussion}

Keeping in mind the extensive use of honey by people of all age groups, this study has been conducted to check the presence of heavy metals and pesticides in honey collected from various areas of Pakistan and honey belonging to some international and national brands. In the present study two type of samples were used, 52 samples from forest belts and agricultural plains while other 25 samples were of different national and international honey brands. Heavy metals zinc, iron and copper were detected in all 52 samples collected from forest belts. Zinc and iron were detected with in their permissible limits with mean concentration of $0.911+0.511$ and $3.42+1.74$ respectively while detected mean concentration of copper was $2.6088+0.644$ which was exceeding almost double to its permissible limit of $1 \mathrm{mg} / \mathrm{kg}$. Manganese and cobalt were also detected in all 52 samples collected from forest belts with mean concentration $0.44+0.59$ and $0.714+0.98$ which were exceeding approximately 2.7 times and 70 times than their permissible limit of $0.16 \mathrm{mg} / \mathrm{kg}$ and $0.01 \mathrm{mg} / \mathrm{kg}$ respectively. Chromium was only detected in one sample out of 52 in concentration of 9ppm which was exceeding approximately four times more than its MRL of $2.3 \mathrm{mg} / \mathrm{kg}$. Risk assessment studies also showed the potential of posing significant health risk of this sample due to chromium. Calculated value of THQ was 3.1875 which was approximately three times more than the THQ's threshold value of 1 . For all other samples in which other metals were detected even exceeding their permissible limit THQ was below 1 . Similarly study for detection of heavy metals in tea brand samples revealed that iron and manganese were found below detection limit while zinc was detected in only one sample and that was also within the permissible limit. Copper was detected in all 25 samples with the mean concentration of 2.964 exceeding its permissible limit of $>1 \mathrm{mg} / \mathrm{kg}$. Out of total 25 samples cobalt was detected in 12 samples with mean concentration of $1.01+0.86 \mathrm{ppm}$ 
exceeding its permissible limit $(0.01 \mathrm{ppm})$ while chromium was detected in only 2 samples exceeding its permissible limit. Risk assessment studies revealed that THQ was not exceeding 1 except for the two in which cobalt was detected. THQ for these two samples was 1.005 and 1.416 respectively. The THQ value exceeding 1 indicated the carcinogenic risk to the consumer of those honey samples.

The other part of this research involves the analysis and determination of traces of pesticide in honey samples collected from forest belts and brand samples. Out of 5 pesticides selected for study only two pesticides i.e., Lamda Cyhalothrin and Bifenthrin were detected in honey samples collected from forest belts and agricultural plains. Lamda Cyhalothrin was detected in 21 samples out of 52 samples in mean concentration of $2.311+1.54$ exceeding approximately 100 times than its Maximum Residual Limit (MRL) (0.02ppm) while bifenthrin was detected in 23 samples out of 52 collected from the forest belts with mean concentration of $15.76+12.7$ which was far above its the permissible limit of 5ppm (Table 1). Risk assessment studies revealed that Health Risk Index (HRI) was within the permissible limit for all samples in which different pesticides were detected with the exception of four samples in which bifenthrin was detected. In these samples HRI was 1.09, 1.6, 1.4 and 1.22 respectively. In the brand samples bifenthrin was detected in 11 samples out of 25 in a mean concentration of $6.97+5.23$ exceeding by approximately 1.35 than its MRL of 5ppm, glyphosate was detected in 5 samples out of 25 with mean concentration of $2.04+1.14$ exceeding its MRL, difenaconazole was detected in 8 samples while Imidacloropid was detected in 10 samples out of 24 samples with mean concentration of $0.736+0.53$ exceeding approximately 14.70 times than its MRL value of $0.05 \mathrm{ppm}$. Presence of pesticides in different honey samples is also supported by other studies (Irungu et al., 2016; López et al., 2014; Eissa et al., 2014). Results of risk assessment studies revealed that HRI was only exceeding its threshold limit of 1 for one sample in which bifenthrin was detected (Table 2). For all other samples HRI was within its permissible limit. There are other studies which also revealed the risk to the consumer's health due to the exposure of heavy metals and pesticides (Waili et al., 2012; Chlebo, 2006).

Presence of heavy metals and pesticides in different samples of honey can be due to the plants from which the nectar honey had been collected by honey bees. Sponsler et al. (2019). There may be different sources of the accumulation of pesticides and heavy metals in the tissues of these plants i.e., soil, polluted water used for irrigation, use of pesticides and insecticides adversely used by the farmers to control pest attack and to enhance their yield, vehicular emissions, industrial activities and adaptation of bad agricultural practices in the surrounding agricultural and industrial area from where the honey has been collected (Tosi et al., 2018; Berenbaum, 2016). Honey bees may thus be poisoned nectar already contaminated by pesticides and heavy metals. They may also be poisoned when they fly through pest

Table 1. Detected concentrations of heavy metals and pesticides.

\begin{tabular}{|c|c|c|c|c|c|c|c|c|c|c|c|}
\hline & \multicolumn{5}{|c|}{ Honey Samples } & \multicolumn{6}{|c|}{ Honey Brand Samples } \\
\hline & Mean & $\mathrm{SD}$ & Min & Max & $\begin{array}{l}\text { Detected } \\
\text { in } \\
\text { samples }\end{array}$ & Mean & SD & Min & Max & $\begin{array}{l}\text { Detected } \\
\text { in } \\
\text { samples }\end{array}$ & $\begin{array}{l}\text { MRLs } \\
\text { (ppm) }\end{array}$ \\
\hline \multicolumn{12}{|l|}{ Heavy Metals } \\
\hline Zinc (ppm) & 0.911 & 0.511 & 0.37 & 3.20 & 52 & 0.9 & nd & nd & nd & 1 & 10 \\
\hline Iron (ppm) & 3.4202 & 1.747 & 2.50 & 14.88 & 52 & nd & nd & nd & nd & nd & 20 \\
\hline Copper (ppm) & 2.6088 & 0.644 & 1.38 & 4.29 & 52 & 2.964 & 0.64 & 1.7 & 4 & 25 & 1 \\
\hline Manganese (ppm) & 0.4407 & SD 0.026 & Min 0.42 & 0.59 & 52 & nd & nd & nd & nd & nd & 0.16 \\
\hline Cobalt (ppm) & 0.714 & 0.12 & 0.45 & 0.98 & 52 & 1.01 & 0.386 & 0.60 & 2 & 12 & 0.01 \\
\hline Chromium (ppm) & 9 & & & & 1 & 5.15 & 6.15 & 0.8 & 9.5 & 2 & 2.3 \\
\hline \multicolumn{12}{|l|}{ Pesticides } \\
\hline Lambda Cyhalothrin (ppm) & 2.311 & 1.54 & 0.71 & 7.33 & 21 & nd & nd & nd & nd & nd & 0.02 \\
\hline $\begin{array}{l}\text { Bifenthrin Concentration } \\
\text { (ppm) }\end{array}$ & 15.76 & 12.7 & 2.46 & 45.41 & 23 & 6.97 & 5.23 & 0.01 & 15.13 & 11 & 5 \\
\hline Glyphosate (ppm) & nd & nd & nd & nd & nd & 2.04 & 1.14 & 0.44 & 3.5 & 5 & 2 \\
\hline Difenaconazole (ppm) & nd & nd & nd & nd & nd & 0.386 & 0.337 & 0.08 & 0.74 & 8 & 0.05 \\
\hline Imidacloropid (ppm) & nd & nd & nd & nd & nd & 0.736 & 0.53 & 0.00 & 1.62 & 10 & 0.05 \\
\hline
\end{tabular}

Table 2. Results of THQ and HRI (risk assessment).

\begin{tabular}{|c|c|c|c|c|}
\hline & \multicolumn{2}{|c|}{ Honey Samples } & \multicolumn{2}{|c|}{ Honey Brand Samples } \\
\hline & THQ & HRI & THQ & HRI \\
\hline \multirow[t]{2}{*}{ Cobalt (ppm) } & -- & -- & 1.005833 & -- \\
\hline & & & 1.4166 & \\
\hline Chromium (ppm) & 3.1875 & -- & -- & -- \\
\hline \multirow[t]{4}{*}{ Bifenthrin Concentration (ppm) } & -- & 1.0927 & -- & 1.072 \\
\hline & & 1.6084 & & \\
\hline & & 1.41305 & & \\
\hline & & 1.22577 & & \\
\hline
\end{tabular}


spray/dust and contaminated air (Biocca et al., 2015). Thus from the alarming results of this study, it may be suggested that honey should be produced by honey bee separate farms with the surrounding area free from contaminations and the local production of honey should be strictly monitored.

\section{Conclusion}

This study revealed that there is considerable amount of heavy metals and pesticides present in honey samples taken from different forest belts and agricultural plains and national and international honey brands. Further, risk assessment studies showed the potential of significant health risk in few samples in which heavy metals and pesticides are detected. As surrounding agricultural, industrial and other anthropogenic activities provide the major source of contamination thus it is suggested that their breeding should be in confined areas following the best management practices.

\section{References}

Abeshu, M. A., \& Geleta, B. (2016). Medicinal uses of honey. Biology and Medicine, 8, 279. http://dx.doi.org/10.4172/0974-8369.1000279.

Ali, H., Khan, E., \& Ilahi, I. (2019). Environmental chemistry and ecotoxicology of hazardous heavy metals: Environmental persistence, toxicity, and bioaccumulation. Journal of Chemistry, 2019, 1-14. http://dx.doi.org/10.1155/2019/6730305.

Berenbaum, M. R. (2016). Does the Honey Bee "Risk Cup" Runneth Over? Estimating aggregate exposures for assessing pesticide risks to honey bees in agroecosystems. Journal of Agricultural and Food Chemistry, 64(1), 13-20. http://dx.doi.org/10.1021/acs.jafc.5b01067. PMid:25885594.

Biocca, M., Fanigliulo, R., Gallo, P., Pulcini, P., \& Pochi, D. (2015). The assessment of dust drift from pneumatic drills using static tests and in-field validation. Crop Protection, 71, 109-115. http://dx.doi. org/10.1016/j.cropro.2015.02.006.

Chlebo, R. (2006). Bees and Pesticides. Pesticides residues in Food Regulation. Monitoring, Policy, 23/24. Modra-Harmonia, Slovakia: Slovakia Publication.

Eissa, F., Sawi, S., \& Zidan, N. H. (2014). Determining Pesticide Residues in Honey and their Potential Risk to Consumers. Polish Journal of Environmental Studies, 23, 1573-1580.

Gregorio, L. S., Bataller, R., Juan, S., \& Escriche, I. (2018). Monitoring honey adulteration with sugar syrups using an automatic pulse voltammetric electronic tongue. Food Control, 91, 254-260. http:// dx.doi.org/10.1016/j.foodcont.2018.04.003.

Gregorio, L. S., Vilanova, S., \& Escriche, I. (2019). Detection of honey adulteration by conventional and real-time PCR. Food Control, 95, 57-62. http://dx.doi.org/10.1016/j.foodcont.2018.07.037.

Group Health Cooperative (2010). Clinical Review Criteria: Medihoney dressing for wound management (Medihoney primary dressing with active Manuka Honey, derma sciences Medihoney dressing with active Manuka Honey). Oakland, California: Group Health Cooperative.

Irungu, J., Raina, S., \& Torto, B. (2016). Determination of pesticide residues in honey: a preliminary study from two of Africa's largest honey producers. Food Contamination, 3(1), 14. http://dx.doi. org/10.1186/s40550-016-0036-4.

Jull, A. B., Walker, N., \& Deshpande, S. (2013). Honey as topical treatment of wounds. The Cochrane Database of Systematic Reviews, 28(2), 5083.

Khan, F. R., Abadin, Z., \& Rauf, N. (2007). Honey: nutritional and medicinal value. International Journal of Clinical Practice, 61(10),
1705-1707. http://dx.doi.org/10.1111/j.1742-1241.2007.01417.x. PMid:17877657.

Khalil, M. I., Sulaiman, S. A., \& Boukraa, L. (2010). Antioxidant properties of honey and its role in preventing health disorder. The Open Nutraceuticals Journal, 3(1), 6-16. http://dx.doi.org/10.2174 /18763960010030100006.

Kumar, K. P., Bhowmik, D., \& Chandira, M. R. (2010). Medicinal uses and health benefits of Honey: An overview. Journal of Chemical and Pharmaceutical Research, 2(1), 385-395.

López, D. R., Ahumada, D. A., Díaz, A. C., \& Guerrero, J. A. (2014). Evaluation of pesticide residues in honey from different geographic regions of Colombia. Food Control, 37, 33-40. http://dx.doi. org/10.1016/j.foodcont.2013.09.011.

Mehretie, S., Al Riza, D. F., Yoshito, S., \& Kondo, N. (2018). Classification of raw Ethiopian honeys using front face fluorescence spectra with multivariate analysis. Food Control, 84, 83-88. http://dx.doi. org/10.1016/j.foodcont.2017.07.024.

Molan, P. C. (2002). Re-introducing honey in the management of wounds and ulcers theory and practice. Ostomy/Wound Management, 48(11), 28-40. PMid:12426450.

Naccari, C., Macaluso, A., Giangrosso, G., Naccari, F., \& Ferrantelli, V. (2014). Risk Assessment of Heavy Metals and Pesticides in Honey From Sicily (Italy). Journal of Food Research, 3(2), 107. http://dx.doi. org/10.5539/jfr.v3n2p107.

Naila, A., Sulaiman, F. A. Z., Ajit, A., \& Weeds, Z. (2018). Classical and novel approaches to the analysis of honey and detection of adulterants. Food Control, 90, 152-165. http://dx.doi.org/10.1016/j. foodcont.2018.02.027.

Molan, P. C. (1999). Why honey is effective as a medicine. 1. Its use in modern medicine. Bee World, 80(2), 80-92. http://dx.doi.org/10.1 080/0005772X.1999.11099430.

Şeyda, K., Ibrahim, K., \& Erşan, K. (2017). Characterization of Turkish honeys regarding of physicochemical properties, and their adulteration analysis. Food Science and Technology, 37(1), 80-89.

Shahid, M., Khalid, S., Bakhat, H., Saeed, M. F., Ashraf, M., Sabir, M., Niazi, N., Bilal, M., Naqvi, T., Irshad, B., Eric, P., (2016). Pesticides Pollution in Agricultural Soils of Pakistan, Azotobacter chroococcum -Potential Biofertilizer in Agriculture: An Overview. In K. R. Hakeem, J. Akhtar \& M. Sabir (Eds.), Soil Science: Agricultural and Environmental Prospectives (pp. 199-229). Switzerland: Springer.

Tosi, S., Costa, C., Vesco, U., Quaglia, G., \& Guido, G. (2018). A 3-year survey of Italian honey bee-collected pollen reveals widespread contamination by agricultural pesticides. The Science of the Total Environment, 615, 208-218. http://dx.doi.org/10.1016/j. scitotenv.2017.09.226. PMid:28968582.

Sohaimy, S. A. E., Masry, S. H. D., \& Shehata, M. G. (2015). Physicochemical characteristics of honey from different origins. Annals of Agricultural Science, 60(2), 279-287. http://dx.doi.org/10.1016/j.aoas.2015.10.015.

Sponsler, D. B. S., Grozinger, C. M., Hitaj, C., Rundlöf, M., Botías, C., Code, A., Lonsdorf, E. V., Melathopoulos, A. P., Smith, D. J., Suryanarayanan, S., Thogmartin, W. E., Williams, N. M., Zhang, M., \& Douglas, M. R. (2019). Pesticides and pollinators: A socioecological synthesis. The Science of the Total Environment, 662, 1012-1027. http://dx.doi.org/10.1016/j.scitotenv.2019.01.016. PMid:30738602.

Tariq, M., Afzal, S., Hussain, I., \& Sultana, N. (2007). Pesticides exposure in Pakistan: A review. Environment International, 33(8), 1107-1122. http://dx.doi.org/10.1016/j.envint.2007.07.012. PMid:17765971.

Waili, N., Salom, K., Ghamdi, A., \& Ansari, M. J. (2012). Antibiotic, pesticide, and microbial contaminants of honey: Human health hazards. The Scientific World Journal, 2012, 9.

Wieczorek, J., Pietrzak, M., Pomianowski, J., \& Wieczorek, Z. (2014). Honey as a source of bioactive compounds. Polish Journal of Natural Sciences, 29(3), 275-285. 